\title{
Ameliorative action of farnesol on cyclophosphamide induced toxicity in mice
}

\author{
Atefeh Araghi ${ }^{1}$, Hannaneh Golshahi ${ }^{2}$, Farshad Baghban ${ }^{3}$, Mohaddeseh Abouhosseini Tabari ${ }^{*}$ \\ ${ }^{1}$ Faculty of Veterinary Medicine, Amol University of Special Modern Technologies, Amol, Iran \\ ${ }^{2}$ Department of Pathology, Faculty of Veterinary Medicine, University of Tehran, Tehran, Iran \\ ${ }^{3}$ Department of Veterinary Medicine, Yasooj Branch, Islamic Azad University, Yasooj, Iran
}

\section{A R T I C L E I N F O}

\section{Article Type:}

Original Article

\section{Article History:}

Received: 25 July 2017

Accepted: 18 November 2017

\section{Keywords:}

Cyclophosphamide

Farnesol

Oxidative stress

Testis

\begin{abstract}
A B S T R A C T
Introduction: Cyclophosphamide is an alkylating agent with antineoplastic and immunosuppressive effects. Acrolein, one of its metabolites, is responsible for different toxic side effects such as oxidative stress, and cell death. The present study aimed to evaluate protective effects of farnesol, a natural terpenoid with antioxidant effects, on cyclophosphamide induced side effects.

Methods: For this purpose, mice received $200 \mathrm{mg} / \mathrm{kg}$ of cyclophosphamide plus 5 or $10 \mathrm{mg} / \mathrm{kg}$ of farnesol as pretreatment for 7 days. At the end of the study, samples from blood and different organs were collected. Histopathological and biochemical analyses including malondialdehyde (MDA), catalase (CAT) and glutathione (GSH) content as well as alanine transaminase (ALT) and aspartate aminotransferase (AST) were done to determine the toxic effects of cyclophosphamide and probable protective effect of farnesol.

Results: Application of farnesol as a pretreatment could reduce tissue damages induced by cyclophosphamide particularly in testis, liver and spleen. The kidney did not show any relapse in tissue damages induced by cyclophosphamide. The testis demonstrated the most improvement by administration of farnesol, and the anti-oxidant enzymes increased in testicular tissues.

Conclusion: This study indicated the protective effect of farnesol against oxidative stress induced by cyclophosphamide in the tissues, especially at the dose of $10 \mathrm{mg} / \mathrm{kg}$ on the testicular tissue. Hence, it might be beneficial in patients who are using cyclophosphamide.
\end{abstract}

Implication for health policy/practice/research/medical education:

Farnesol as an antioxidant agent was able to provide some protection against toxic effects of cyclophosphamide especially on testes tissues. Hence it might be useful in patients using this drug.

Please cite this paper as: Araghi A, Golshahi H, Baghban F, Abouhosseini Tabari M. Ameliorative action of farnesol on cyclophosphamide induced toxicity in mice. J Herbmed Pharmacol. 2018;7(1):37-43. doi: 10.15171/jhp.2018.07.

\begin{abstract}
Introduction
Cyclophosphamide (CP; N, N-bis (2-chloroethyl) tetrahydro-2H-1, 3, 2-oxazaphosphorin-2-amine 2-oxide) (Figure 1A), is an alkylating agent with antineoplastic and immunosuppressive effects used for the treatment of malignancies including lymphomas, breast cancer, leukemia, multiple myeloma and some diseases such as, rheumatoid arthritis, systemic lupus erythematosus (SLE), and in blood stem cell transplantation in humans and animals $(1,2)$. CP, through bioactivation by hepatic microsomal cytochrome $\mathrm{P} 450$, produces two active metabolites: phosphoramide mustard and acrolein
\end{abstract}

(3). The antineoplastic effects of $\mathrm{CP}$ are related to phosphoramide mustard, but acrolein is responsible for several toxic effects such as, induction of oxidative stress, cell death (apoptotic necrosis and oncotic necrosis) (4). Alleviation of toxic effects of $\mathrm{CP}$ in different organs has been investigated by using some antioxidant agents (5-11). Farnesol, a 15-carbon sesquiterpene (Figure 1B), is produced in cells by dephosphorylation of farnesyl pyrophosphate (FPP), a metabolic precursor of squalene producing sterols and other isoprenoid compounds. Dietary sources of the farnesol are plant products including fruits and berries (e.g. apricots, peaches, plums,

*Corresponding author: Mohaddeseh Abouhosseini Tabari, 24th Aftab, Faculty of Veterinary Medicine, Amol University of Special Modern Technologies, Amol, Iran. Tel: +981144265008, Email: m.abouhosseini@ ausmt.ac.ir 


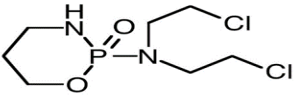

(A)

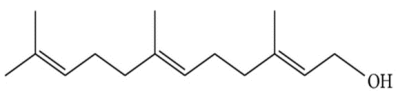

(B)
Figure 1. Chemical structure of cyclophosphamide (A) and farnesol (B).

blueberries, cranberries, raspberries, and strawberries), vegetables (e.g. tomatoes), herbs (e.g. lemongrass and chamomile). It is also obtained from the essential oils of ambrette seeds, and citronella (12). Several studies have demonstrated the protective effect of farnesol against oxidative stress and reduction of tissue damage $(12,13)$. The aim of this study was investigating the protective effect of farnesol against toxic effects induced by CP in a mouse model.

\section{Materials and Methods}

Chemicals

Cyclophosphamide was obtained from Endoxan Baxter ${ }^{\circledR}$ Oncology $\mathrm{GmbH}$, Germany. Farnesol was purchased from Sigma-Aldrich (St Louis, MO, USA). According to Sigma Company, the degree of purity was more than 97\%. Farnesol was emulsified with $0.2 \%$ Tween 80 (Sigma, USA) for preparation of injection solutions. All other chemical substances used in oxidative stress tests were analytical grade and commercially available.

Animals and experiment protocol

The adult male Swiss Albino mice (25-32 g) were acclimatized for 7 days before initiation of experiment. Mice were given standard chow and tap water ad libitum. They were housed in caging system in an air-conditioned room with $12 / 12 \mathrm{~h}$ light-dark cycles, where the temperature $\left(22 \pm 2^{\circ} \mathrm{C}\right)$ and relative humidity $(60 \%-65 \%)$ were kept constant. All animal experimental procedures were under rules of the Animal Ethics Committee of Pasteur Institute of Iran. The animal protocol was planned to minimize pain and discomfort to the animals and every effort was made to minimize animal suffering.

Thirty-two mice were divided into four groups randomly consisting of eight animals in each group $(n=8)$. Group A (control), received the vehicle $(0.2 \%$ Tween 80 in normal saline). Group B received a single dose of CP at $200 \mathrm{mg} / \mathrm{kg}$ b.w (body weight), i.p (intraperitoneally). Group C received farnesol in $5 \mathrm{mg} / \mathrm{kg}$ b.w, i.p for 7 days as pretreatment and following that a single dose of CP in 200 $\mathrm{mg} / \mathrm{kg}$ b.w, i.p. Group D received farnesol in $10 \mathrm{mg} / \mathrm{kg}$ b.w, i.p for 7 days as pretreatment and following that a single dose of CP in $200 \mathrm{mg} / \mathrm{kg}$ b.w, i.p.

\section{Sampling}

The blood sample $(2 \mathrm{~mL})$ was collected directly by cardiac puncture under light anesthesia, aspirated with sterile syringes without anticoagulant and centrifuged to separate the serum and was stored in microcentrifuge tubes. Then animals were euthanized and during necropsy, samples from different organs including liver, spleen, kidney, and testis were collected in separate containers containing $10 \%$ neutral buffered formalin for histopathological examination. Some samples of testes from each group were stored at $-80^{\circ} \mathrm{C}$ for further analysis. Blood samples were centrifuged ( $3000 \mathrm{rpm}$ for 15 minutes at $4^{\circ} \mathrm{C}$ ) to separate serum and stored at $-80^{\circ} \mathrm{C}$ for subsequent analyses.

\section{Histopathologic analysis}

After complete fixation of tissue samples from each group, the samples were processed in tissue processor. Then paraffin embedded blocks were prepared and cut in 5-micron thickness using a microtome and were stained with hematoxylin and eosin ( $\mathrm{H} \& \mathrm{E})$ method. The stained samples were examined using a light microscope.

\section{Biochemical analysis}

For the demonstration of protective effects of farnesol against testicular injuries induced by $\mathrm{CP}$, oxidative stress markers were investigated in testicular tissues. Thus, the testicular tissues were collected and rinsed with ice-cold saline and stored at $-80^{\circ} \mathrm{C}$. Before biochemical analysis, the tissues from testes were homogenized at $4^{\circ} \mathrm{C}$ after adding pre-cooled $0.9 \%$ saline in a ratio of $1: 9$. When tissues were disrupted, the homogenates were centrifuged at $3000 \mathrm{rpm}$ for 10 minutes at $4^{\circ} \mathrm{C}$. The supernatants were used for biochemical measurements. Protein contents of the tissue homogenates were determined using the colorimetric method of Lowry et al with bovine serum albumin as the standard (14).

The formation of thiobarbituric acid in testicular samples were assessed to measure the lipid peroxidation, according to an original method (15) for determination of malondialdehyde (MDA) formation. Briefly, the supernatants of the tissue homogenates were mixed with 20\% trichloroacetic acid and the mixtures were centrifuged. Then thiobarbituric acid was added to the supernatants and heated. The absorbance of the supernatants was measured at $532 \mathrm{~nm}$.

For catalase (CAT) analysis, 10\% tissue homogenates were prepared in $2 \mathrm{~mL}$ of potassium phosphate buffer ( $\mathrm{pH}$ 7.4). These homogenates were centrifuged at $3000 \mathrm{rpm}$ for 15 minutes. CAT activity was measured in the supernatants obtained after centrifugation. $2.95 \mathrm{~mL}$ of $19 \mathrm{mM} \mathrm{H} 2 \mathrm{O} 2$ was poured into the cuvettes. $0.05 \mathrm{~mL}$ of cytosolic supernatant was added to them and the changes in 240 $\mathrm{nm}$ absorbance were recorded at 1 minute intervals for 3 minutes. It is known that the presence of CAT decomposes $\mathrm{H} 2 \mathrm{O} 2$ leading to a reduction in absorbance (16).

The glutathione (GSH) contents were measured according to a previous study for measuring of total GSH (17). The tissues were rinsed 3 times with phosphate buffered saline (PBS). Tissue solutions were mixed with $20 \%$ 
trichloroacetic acid. The samples were centrifuged. The supernatants were mixed with 4 volume of Tris-buffered saline (TBS). Then, $1 \mathrm{mM}$ DTNB [(5, 5'-Dithiobis(2-nitrobenzoic acid)] was added to the samples and incubated for 30 minutes. The absorbance was read at 412 $\mathrm{nm}$.

The serum alanine aminotransferase (ALT) and aspartate aminotransferase (AST), activities were determined by specific commercial kits, and expressed as unit per liter. All samples were tested in duplicate.

\section{Statistical analysis}

Results were expressed as mean \pm SEM (standard error of mean) values. The data were analyzed by means of analysis of variance (ANOVA) followed by Duncan's test. $P$ values of $<0.05$ were considered as statistically significant. All the statistical analyses were done by SPSS version 16 .

\section{Results}

Histopathological evaluation

For histopathological evaluation of the protective properties of farnesol against cellular toxic effects of CP, tissue samples of livers, spleens, kidneys and testes were collected from each group and examined histologically, after processing. The results are presented in Figure 2. Liver: In group $\mathrm{A}$, microscopic examination showed normal histological structure (Figure 2, 1A). In group B, loss of hepatic architecture, moderate to severe diffuse vacuolar degeneration, necrotic hepatocytes, dilated and congested sinusoidal spaces, infiltration of mononuclear inflammatory cells between degenerated hepatocytes and moderate portal hepatitis were noted. In some areas, severe empty vacuoles associated with strands of necrotic hepatocytes were detected. Also, some dysplastic
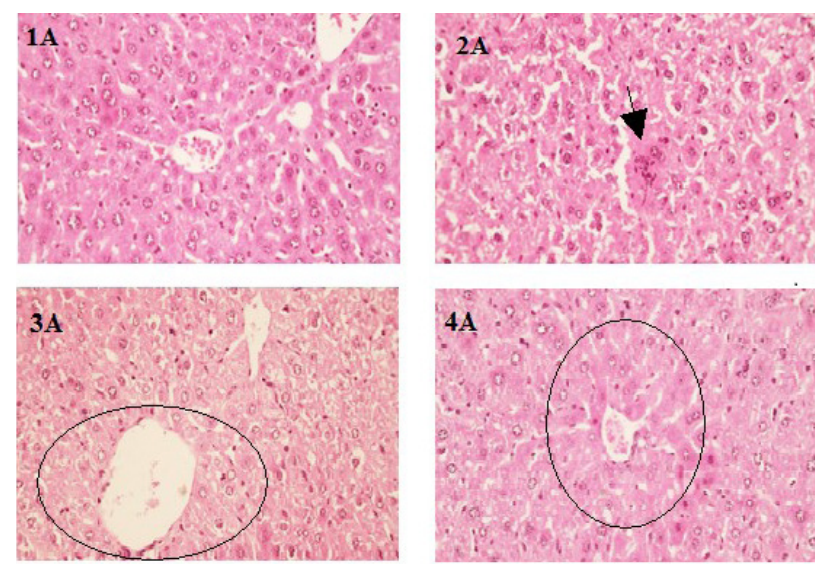

Figure 2. Histopathological effect of farnesol on cellular liver toxicity of Cyclophosphamide (CP).

1A- Normal structure of liver. 2A- In CP-treated mice, loss of hepatic architecture, degeneration and necrosis of hepatocytes (arrow) are seen. 3A-Amelioration in hepatic injuries is seen in the mice which received farnesol in $5 \mathrm{mg} / \mathrm{kg}$ (circle). $4 \mathrm{~A}$ - In the mice which received farnesol in $10 \mathrm{mg} / \mathrm{kg}$, the liver demonstrates its normal histological structure comparatively (circle). (H\&E) $\times 100$. hepatocytes and large polymorphic and hyperchromatic hepatocyte were seen (Figure 2, 2A). Lower dose of farnesol (group C) did not prevent the toxic effects of CP, so, dilatation and congestion of sinusoids, coagulative necrotic areas, dysplastic hepatocytes were still present. In the mice of group $\mathrm{D}$ which received higher dose of farnesol, noticeably ameliorated hepatic injury induced by $\mathrm{CP}$ was observable. The liver demonstrated its normal histological structure relatively. Marked decrease of vacuolar degeneration and necrosis of most hepatocytes with minimized dysplastic changes, less dilation of central and portal veins, and obvious reduction of sinusoids congestion were noted. Regeneration of hepatocytes was detected by the presence of binucleated cells (Figure 2, $3 \mathrm{~A}$ and $4 \mathrm{~A})$.

Spleen: In group A, examination of sections of spleen revealed normal structure of red and white pulps (Figure 3, 1B). In CP-treated mice, general disorganization and obvious loss in distinction between the red and white pulps were noted and also, decrease in the lymphocyte population, necrotic lymphocytes, congestion and increased hemosiderosis were seen (Figure 3, 2B). In group $\mathrm{C}$, little improvement as apparent distinction between the red and white pulps was noted. A large number of the megakaryocytes and pigment-laden macrophages could also be detected in the red pulp accompanied with slight to marked atrophy of white pulp (Figure 3, 3B). In group $\mathrm{D}$ which received farnesol $10 \mathrm{mg} / \mathrm{kg}$, the histopathological alterations were declined and a clear improvement was seen (Figure 3, 4B).

Kidney: In group $\mathrm{A}$, histological examination of kidneys revealed normal architecture (Figure $4,1 \mathrm{C}$ ). In group B, administration a single dose of CP caused nephrotoxicity which was characterized by extensive degenerative
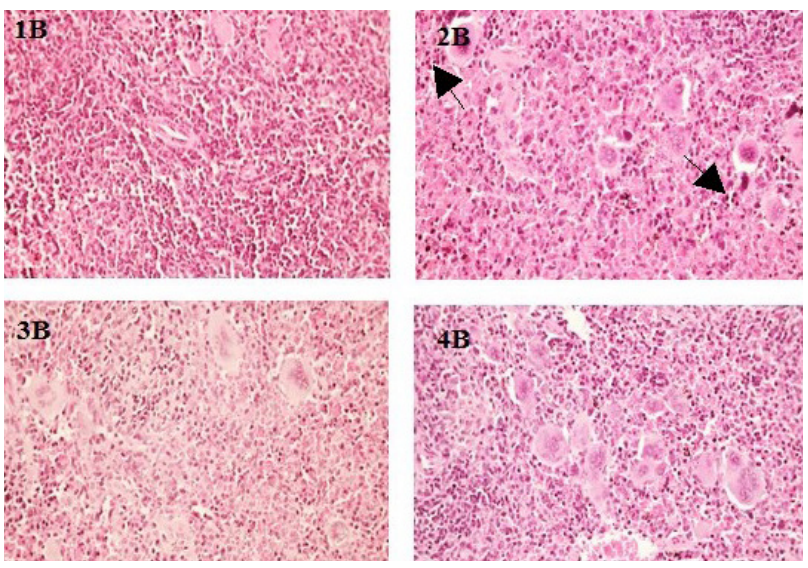

Figure 3. Histopathological effect of farnesol on spleen toxicity induced by cyclophosphamide (CP).

1B- Normal structure of red and white pulps of spleen. 2B- In CPtreated mice, general disorganization, apparent loss of distinction between the red and white pulps and necrotic lymphocytes (arrows) were noted. 3B- Little improvement was seen as evident distinction between the red and white pulps in the mice which received farnesol in $5 \mathrm{mg} / \mathrm{kg}$. 4B- Obvious improvement was seen in the spleen structure of mice that received farnesol in $10 \mathrm{mg} / \mathrm{kg}$. $(\mathrm{H} \& \mathrm{E}) \times 100$. 
changes, necrosis, desquamation of epithelial cells of tubules, shrinkage of the glomeruli and congestion (Figure $4,2 \mathrm{C}$ ). The mice of group $\mathrm{C}$ and $\mathrm{D}$ which were respectively pretreated with farnesol 5 and $10 \mathrm{mg} / \mathrm{kg}$, demonstrated no significant alleviation of renal injuries induced by $\mathrm{CP}$ (Figure 4, 3C and 4C).

Testis: In group $\mathrm{A}$, the thick seminiferous epithelium with different stages of the spermatogenic cells and welldeveloped Leydig cells in the interstitial spaces were observed (Figure 5, 1D). In the CP-treated mice, there was disorganization and distortion of the seminiferous tubules, vacuolization and moderated to severe atrophy of the seminiferous tubules. Degenerative and destructive sings were noted in both spermatogenic lineage and interstitial cells. The seminiferous epithelium was thinner compared with the control group. Congestion was noted in the interstitial tissue and under the tunica albuginea. Exfoliated germ cells and multinucleated giant were accumulated in the lumen of the tubules. The interstitial tissue was loosely packed around the seminiferous tubules (Figure 5, 2D). In group C, the severity of histopathologic lesions was lower in comparison with those in the mice of group B (Figure 5, 3D), but an advanced improvement was seen in the testes of mice treated with $10 \mathrm{mg} / \mathrm{kg}$ farnesol (group D). Most of the seminiferous tubules restored to its normal structure with the presence of all spermatogenic layers. The seminiferous tubules content of sperm and spermatocyte was relatively the same as with the control group. The number of Leydig cells increased and the nuclei of the Sertoli cells were returned to their natural shapes (Figure 5, 4D).

\section{Biochemical evaluation}

Because the testis showed the best response in the farnesol treated groups, so the oxidative stress markers were
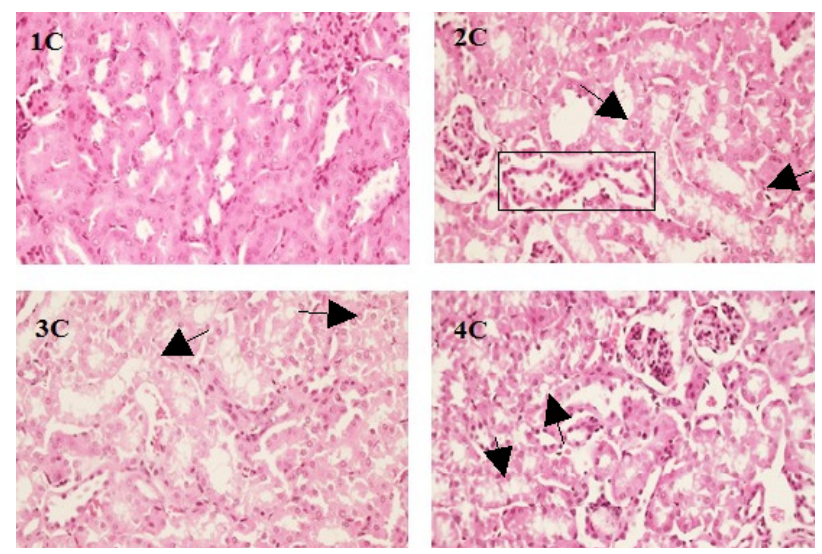

Figure 4. . Histopathological effect of farnesol on renal toxicity induced by Cyclophosphamide (CP).

1C- Normal structure of renal tubules. 2C- In CP-treated mice, there was extensive degenerative changes (arrows), necrosis (rectangle), desquamation of epithelial cells of tubules in the kidneys. $3 \mathrm{C}$ and 4C- farnesol with 5 and $10 \mathrm{mg} / \mathrm{kg}$ could not alleviate the renal injuries induced by $\mathrm{CP}$. Note to degenerative changes in figure $3 \mathrm{C}$ and $3 \mathrm{D}$ (arrows). (H\&E) $\times 100$. measured in its tissues. For evaluation of oxidative stress in testis, the amounts of MDA, GSH and CAT were compared between the control group (group A) and three other groups (B, C and D). The results of oxidative stress tests are presented in Table 1. The MDA after administration of $\mathrm{CP}$ in group $\mathrm{B}$ showed a marked increase compared to the control group $(P<0.01)$, but after using farnesol for 7 days as pretreatment in groups $\mathrm{C}(5 \mathrm{mg} / \mathrm{kg})$ and $\mathrm{D}(10 \mathrm{mg} / \mathrm{kg})$, the amount of MDA reduced, however significant decrease was only detected in group $\mathrm{D}(P<0.05)$. Regarding GSH, the amount in control group (group A) was high, but after using $\mathrm{CP}$ in group $\mathrm{B}$, the $\mathrm{GSH}$ decreased significantly $(P<0.05)$. After using farnesol as a pretreatment in groups $\mathrm{C}$ and $\mathrm{D}$, the amount of GSH increased, however the significant increase was seen in group D compared to the CP group $(P<0.05)$. The level of CAT decreased after administration of $\mathrm{CP}$, but following pretreatment with farnesol in groups $\mathrm{C}$ and $\mathrm{D}$, the amount of CAT increased however; it was not statically significant $(P>0.05)$

For evaluation of hepatic injuries and showing protective properties of farnesol against cellular toxic effects of CP, AST and ALT were measured serum and compared in the groups. There were statistically significant differences $(P<0.05)$ between groups B and D and between A and B. The results are presented in Table 2.

\section{Discussion}

$\mathrm{CP}$ is used as an antineoplastic agent for treatment of various cancers. This chemotherapeutic agent has several clinical side effects which have limited its clinical applications (18). Although, the mechanisms by which CP develop toxic effects are not well known, but several studies have demonstrated that these side effects may be attributable to interruption of redox stability of tissues
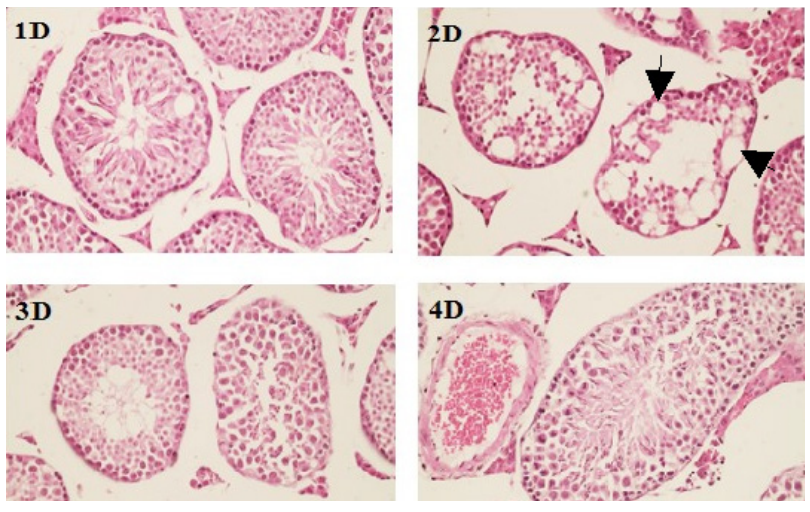

Figure 5. Histopathological effect of farnesol on testis toxicity induced by Cyclophosphamide (CP).

1D- Normal structure of testis. Thick seminiferous epithelium was observed with different stages of the spermatogenic cells and Leydig cells in the interstitial spaces. 2D- In CP-treated mice, disorganization and distortion of the seminiferous tubules, vacuolization (arrows), moderate to severe atrophy of the seminiferous tubules were detected. 3D- The severity of histopathologic lesions was less in testes of mice, which received farnesol in $5 \mathrm{mg} / \mathrm{kg}$. 4D- Advanced improvement was seen in the testes of mice, which received farnesol in $10 \mathrm{mg} / \mathrm{kg}$. (H\&E) $\times 100$. 
Table 1. Oxidative stress in testicular tissue in different treatment groups

\begin{tabular}{lccc}
\hline Groups & $\begin{array}{c}\text { MDA } \\
\text { (nmol/g) }\end{array}$ & $\begin{array}{c}\text { GSH } \\
\text { (nmol/mg) }\end{array}$ & $\begin{array}{c}\text { CAT } \\
\text { (U/mg protein) }\end{array}$ \\
\hline A (CON) & $4.01 \pm 0.82$ & $0.91 \pm 0.13$ & $44.72 \pm 5.2$ \\
B (CP) & $8.28 \pm 0.66^{\mathrm{a}}$ & $0.52 \pm 0.11^{\mathrm{a}}$ & $33.22 \pm 3.3^{\mathrm{a}}$ \\
C (CP+Far5) & $6.28 \pm 0.71$ & $0.65 \pm 0.11$ & $36.27 \pm 6.5$ \\
D (CP+Far10) & $5.08 \pm 0.62^{\mathrm{b}}$ & $0.77 \pm 0.12^{\mathrm{b}}$ & $39.1 \pm 6.1$ \\
\hline
\end{tabular}

A (CON): Control group, $B(C P)$ : receiving cyclophosphamide, C $(\mathrm{CP}+\mathrm{Far} 5)$ : receiving cyclophosphamide + farnesol $5 \mathrm{mg} / \mathrm{kg}, \mathrm{D}$ (CP+Far10): receiving cyclophosphamide + farnesol $10 \mathrm{mg} / \mathrm{kg}$. MDA: malondialdehyde; GSH: glutathione; CAT: catalase.

Values are expressed as mean \pm SEM.

a $P<0.05$ in comparison with control group.

${ }^{\mathrm{b}} P<0.05$ in comparison with $\mathrm{CP}$ group.

Table 2. The amounts of aspartate aminotransferase (AST) and alanine aminotransferase (ALT) in different treated groups

\begin{tabular}{lcccc}
\hline Groups & A (Control) & B (CP) & C (CP+Far5) & D (CP+Far10) \\
\hline AST & $189.28 \pm 10.71$ & $250.57 \pm 7.40^{\mathrm{a}}$ & $210.26 \pm 11.46$ & $192 \pm 8.72^{\mathrm{b}}$ \\
ALT & $116.2 \pm 22.94$ & $148 \pm 24.73^{\mathrm{a}}$ & $135 \pm 10.17^{\circ}$ & $110.1 \pm 9.46^{\mathrm{b}}$ \\
\hline
\end{tabular}

A (CON): Control group, B (CP): receiving cyclophosphamide, C $(\mathrm{CP}+$ Far5): receiving cyclophosphamide + farnesol $5 \mathrm{mg} / \mathrm{kg}, \mathrm{D}$ $(\mathrm{CP}+$ Far10): receiving cyclophosphamide + farnesol $10 \mathrm{mg} / \mathrm{kg}$. Values are expressed as mean \pm SEM.

a $P<0.05$ in comparison with control group.

${ }^{\mathrm{b}} P<0.05$ in comparison with $\mathrm{CP}$ group.

which result in oxidative stress and production of free radicals and reactive oxygen species $(6,19)$.

Acrolein, the main metabolite of $\mathrm{CP}$, is responsible for producing free radicals through interaction with the body's antioxidant defense system. The free radicals are highly reactive and cause oxidation of various enzymes (20). Acrolein leads to cellular damage after binding with the GSH and reduction of its level in the cell (21). As a result, acrolein impairs the GSH dependent antioxidant system and amplifies free radical production (22). CP induces DNA damage through an oxidative process, which is caused by the generation of $\mathrm{H}_{2} \mathrm{O} 2$ (23). In the present study, the amount of GSH in CP-treated group decreased significantly $(P<0.05)$ and after using farnesol as pretreatment, the amount of GSH increased.

Membrane lipids have high susceptibility to damages induced by free radicals. Lipids after reacting with free radicals show lipid peroxidation (24). Lipid peroxidation is one of the main reasons of cyclophosphamideinduced toxicity due to the production of acrolein. Lipid peroxidation is the fundamental factor of oxidative stress and MDA, a breakdown product of polyunsaturated fatty acid oxidation, is used as a marker of lipid peroxidation in tissues (1). In our study, the level of MDA after administration of CP demonstrated a marked increase compared to control group, but by using farnesol for 7 days as pretreatment, the amount of MDA reduced.

To avoid the side effects, CP is used in combination with various detoxifying agents like antioxidants. Free radical scavengers and antioxidants can be used as simultaneous treatment (11). In the present study, the level of CAT decreased after administration of $\mathrm{CP}$, but following application of farnesol as pretreatment, the amount of CAT increased. Therefore, farnesol could be used as a pretreatment medicine before administration of $\mathrm{CP}$ to prevent $\mathrm{CP}$ toxic effects.

The researchers have emphasized on the anticipatory effects of farnesol against hazardous materials. Qamar et al investigated the chemoprotective effects of farnesol in rats, which were intratracheally exposed to the carcinogen, benzo (a) pyrene. A pretreatment with farnesol was able to improve the inflammation, edema, surfactant dysfunction and injuries caused by this carcinogen (25).

Farnesol seems to be a very interesting and promising compound for its antioxidant, anti-inflammatory and chemopreventive properties. Khan and Sultana showed its anticipatory effect against DMH (1,2-dimethylhydrazine) -induced oxidative stress, inflammatory response and apoptosis in the colon of Wistar rats. The study indicated that a prophylactic treatment with farnesol could increase the antioxidant enzymes such as superoxide dismutase, CAT, GSH peroxidase, GSH reductase, glutathioneS-transferase and quinone reductase and the cellular antioxidant-reduced GSH (12).

In the present study, the testes had the best results in tissue restoration by using farnesol as pretreatment medication. Histopathological examination of testes showed the protective effect of farnesol. In group B the administration of $\mathrm{CP}$ produced tissue damage in testes, but in group $\mathrm{D}$ which received farnesol $10 \mathrm{mg} / \mathrm{kg}$, the testicular injuries induced by $\mathrm{CP}$ was mitigated by farnesol completely. The deleterious effects of $\mathrm{CP}$ on testis have previously shown in other studies. In a study, single dose (200 mg/kg b.w, i.p) of $\mathrm{CP}$ injected to healthy male mice caused a very significant $(P<0.001)$ reduction in diverse spermatogonia cells in seminiferous tubules in comparison with control group (1). Several studies have shown testicular toxic effects of CP (26-28). Testicular toxicity may occur in result of the increase in the intracellular levels of ROS, which are toxic at high levels and can interact with macromolecules (1). In this study, farnesol as an antioxidant agent decreased the level of oxidative products and increased the tissue level of antioxidant enzymes. When the farnesol was used as a pretreatment medicine in treated groups, the amount of MDA decreased significantly in comparison with $\mathrm{CP}$ group (group B) but the antioxidant enzymes such as CAT and GSH increased. There is a common agreement that male reproductive organ is especially susceptible to the toxic effects of ROS and lipid peroxidation which eventually result in infertility and CP has a critical role in the production of these toxic agents $(29,30)$. Farnesol was able to show an ameliorative effect on CP induced testicular injuries. In our previous study, our team has reported the protective effect of carvacrol, a terpenoid 
compound, on ketamine induced testicular damage. Like farnesol, the protective effect of carvacrol was through its antioxidant properties (31).

In this study, when farnesol was used as a pretreatment medicine, both liver and spleen showed tissue improvement. For the demonstration of regression of hepatic injuries induced by $\mathrm{CP}$, the activities of the hepatic enzymes such as ALT and AST were evaluated. The activities of the hepatic enzymes such as ALT and AST in the plasma are reliable indicators of hepatic injuries (32). Elevated plasma levels of these enzymes by CP resulted from cellular damages and loss of functional integrity of hepatocyte membrane leading to their leakage into the serum or plasma (9). AST is an enzyme abundant in the cytoplasm and mitochondria of hepatocytes and presents in heart, skeletal muscle, and brain. ALT is a specific hepatic enzyme which principally is found in the cytoplasm of hepatocytes (33). Serologic results of this study showed that farnesol was able to produce hepatoprotective effect particularly when it was used at $10 \mathrm{mg} / \mathrm{kg}$ b.w, i.p. These results were compatible with histopathologic findings of this research, which confirmed the chemoprotective effect of farnesol against CP induced hepatic injuries.

Toxic metabolites produced during bioactivation of $\mathrm{CP}$ in the hepatocytes have an important role in $\mathrm{CP}$ induced nephrotoxicity (11). Additionally, renal cell damage induced by CP is caused after binding of acrolein with GSH and reduction of its level in cells (21). The nephrotoxicity of CP includes a variable reduction of glomerular filtration rate as well as tubular dysfunction (34). Histologically the CP treated rat kidneys showed glomerular nephritis, interstitial edema and cortical tubular vacuolization. Lysosomal enzymes activities decreased and protein content increased in the kidneys of $\mathrm{CP}$ treated rats. The reduction in the lysosomal enzymes activities, may contribute to renal damage (35). At this study, unfortunately there was not any significant healing in the kidneys of treated groups. This may be explained due to the severity of injuries induced by $\mathrm{CP}$ in renal tubular cells and glomeruli and the limited regeneration capacity of renal cells $(11,36,37)$.

As a conclusion, farnesol as an antioxidant agent was able to provide some protection against toxic effects of $\mathrm{CP}$, but for complete inhibition of CP induced tissue damages, the application of farnesol as a pretreatment medication requires more investigation with more details in future studies.

\section{Conflict of interests}

Authors have no conflict of interest.

\section{Authors' contributions}

All authors made substantial contributions to conception and design, and/or acquisition of data, and substantially to the writing of the manuscript. All authors read the final version and confirmed the manuscript publication.

\section{Ethical considerations}

The research was in accordance with Pasteur Institute of Iran laboratory animals' guide and was accepted by the ethics committee of this institute (Ethical No. 940612). All efforts were made to minimize the animals' suffering and to reduce the number of the animals used.

\section{Funding/Support}

The present study was financially supported by Amol University of Special Modern Technologies. (Grant No. 94-27).

\section{References}

1. Chabra A, Shokrzadeh M, Naghshvar F, Salehi F, Ahmadi A. Melatonin ameliorates oxidative stress and reproductive toxicity induced by cyclophosphamide in male mice. Hum Exp Toxicol. 2014;33(2):185-95. doi: 10.1177/0960327113489052.

2. Zarei M, Shivanandappa T. Amelioration of cyclophosphamide-induced hepatotoxicity by the root extract of Decalepis hamiltonii in mice. Food Chem Toxicol. 2013;57:179-84. doi: 10.1016/j.fct.2013.03.028.

3. Ludeman SM. The chemistry of the metabolites of cyclophosphamide. Curr Pharm Des. 1999;5(8):627-43.

4. Kern JC, Kehrer JP. Acrolein-induced cell death: a caspaseinfluenced decision between apoptosis and oncosis/ necrosis. Chem Biol Interact. 2002;139(1):79-95.

5. Rai SS, Somashekar B, Gowda KPS. Cardioprotective effects of ethanolic leaf extract of ipomoea batatas on doxorubicin induced cardiotoxicity in rats. Asian J Pharm Clin Res. 2015;8(2):444-50.

6. Das UB, Mallick M, Debnath JM, Ghosh D. Protective effect of ascorbic acid on cyclophosphamide- induced testicular gametogenic and androgenic disorders in male rats. Asian J Androl. 2002;4(3):201-7.

7. Shalizar Jalali A, Hassanzadeh S, Malekinejad H. Chemoprotective effect of Crataegus monogyna aqueous extract against cyclophosphamide-induced reproductive toxicity. Vet Res Forum. 2011;2(4):266-73.

8. Manda K, Bhatia AL. Prophylactic action of melatonin against cyclophosphamide-induced oxidative stress in mice. Cell Biol Toxicol. 2003;19(6):367-72.

9. Olayinka ET, Ore A, Ola OS, Adeyemo OA. Ameliorative Effect of Gallic Acid on Cyclophosphamide-Induced Oxidative Injury and Hepatic Dysfunction in Rats. Med Sci (Basel). 2015;3(3):78-92. doi: 10.3390/medsci3030078.

10. Rostampur S, Hosseinpour Feizi MA, Banan Khojasteh SM, Daluchi F. Heracleum persicum extract improves cyclophosphamide-induced liver toxicity and oxidative stress in male rats. Adv Herb Med. 2016;2(2):29-35.

11. Singh M, Kumar N, Shuaib M, Garg VK, Sharma A. A Review on Renal Protective Agents for Cyclophosphamide Induced Nephrotoxicity. World J Pharm Pharm Sci. 2014;3(3):737-47.

12. KhanR,SultanaS.Farnesolattenuates 1,2-dimethylhydrazine induced oxidative stress, inflammation and apoptotic responses in the colon of Wistar rats. Chem Biol Interact. 2011;192(3):193-200. doi: 10.1016/j.cbi.2011.03.009. 
13. Shahnouri M, Abouhosseini Tabari M, Araghi A. Neuropharmacological properties of farnesol in Murine model. Iran J Vet Res. 2016;17(4):259-64.

14. Lowry OH, Rosebrough NJ, Farr AL, Randall RJ. Protein measurement with the Folin phenol reagent. J Biol Chem. 1951;193(1):265-75.

15. Sicinska P, Bukowska B, Michalowicz J, Duda W. Damage of cell membrane and antioxidative system in human erythrocytes incubated with microcystinLR in vitro. Toxicon. 2006;47(4):387-97. doi: 10.1016/j. toxicon.2005.12.006.

16. Aebi H. Catalase in vitro. Methods Enzymol. 1984;105:1216.

17. Gibson XA, Shartava A, McIntyre J, Monteiro CA, Zhang Y, Shah A, et al. The efficacy of reducing agents or antioxidants in blocking the formation of dense cells and irreversibly sickled cells in vitro. Blood. 1998;91(11):4373-8.

18. Fraiser LH, Kanekal S, Kehrer JP. Cyclophosphamide toxicity. Characterising and avoiding the problem. Drugs. 1991;42(5):781-95

19. Ghosh D, Das UB, Ghosh S, Mallick M, Debnath J. Testicular gametogenic and steroidogenic activities in cyclophosphamide treated rat: a correlative study with testicular oxidative stress. Drug Chem Toxicol. 2002;25(3):281-92. doi: 10.1081/dct-120005891.

20. Senthilkumar S, Yogeeta SK, Subashini R, Devaki T. Attenuation of cyclophosphamide induced toxicity by squalene in experimental rats. Chem Biol Interact. 2006;160(3):252-60. doi: 10.1016/j.cbi.2006.02.004.

21. Ohno Y, Ormstad K. Formation, toxicity and inactivation of acrolein during biotransformation of cyclophosphamide as studied in freshly isolated cells from rat liver and kidney. Arch Toxicol. 1985;57(2):99-103.

22. Yousefipour Z, Ranganna K, Newaz MA, Milton SG. Mechanism of acrolein-induced vascular toxicity. J Physiol Pharmacol. 2005;56(3):337-53.

23. Murata M, Suzuki T, Midorikawa K, Oikawa S, Kawanishi S. Oxidative DNA damage induced by a hydroperoxide derivative of cyclophosphamide. Free Radic Biol Med. 2004;37(6):793-802. doi: 10.1016/j. freeradbiomed.2004.05.009.

24. Devasagayam TP, Tilak JC, Boloor KK, Sane KS, Ghaskadbi SS, Lele RD. Free radicals and antioxidants in human health: current status and future prospects. J Assoc Physicians India. 2004;52:794-804.

25. Qamar W, Khan AQ, Khan R, Lateef A, Tahir M, Rehman MU, et al. Benzo(a)pyrene-induced pulmonary inflammation, edema, surfactant dysfunction, and injuries in rats: alleviation by farnesol. Exp Lung Res. 2012;38(1):1927. doi: 10.3109/01902148.2011.632064.

26. Anderson D, Bishop JB, Garner RC, Ostrosky-Wegman P, Selby PB. Cyclophosphamide: review of its mutagenicity for an assessment of potential germ cell risks. Mutat Res. 1995;330(1-2):115-81

27. Kaur F, Sangha GK, Bilaspuri GS. Cyclophosphamideinduced structural and biochemical changes in testis and epididymidis of rats. Indian J Exp Biol. 1997;35(7):771-5.

28. Meistrich ML, Parchuri N, Wilson G, Kurdoglu $B$, Kangasniemi M. Hormonal protection from cyclophosphamide-induced inactivation of rat stem spermatogonia. J Androl. 1995;16(4):334-41.

29. Elangovan N, Chiou TJ, Tzeng WF, Chu ST. Cyclophosphamide treatment causes impairment of sperm and its fertilizing ability in mice. Toxicology. 2006;222(12):60-70. doi: 10.1016/j.tox.2006.01.027.

30. Tripathi DN, Jena GB. Astaxanthin inhibits cytotoxic and genotoxic effects of cyclophosphamide in mice germ cells. Toxicology. 2008;248(2-3):96-103. doi: 10.1016/j. tox.2008.03.015.

31. Araghi A, Abouhosseini Tabari M, Golshahi H. Protective effect of carvacrol on ketamine induced testicular damage in mouse model of schizophrenia. J HerbMed Pharmacol. 2017;6(3):100-6.

32. Amacher DE. Serum transaminase elevations as indicators of hepatic injury following the administration of drugs. Regul Toxicol Pharmacol. 1998;27(2):119-30. doi: 10.1006/ rtph.1998.1201.

33. Nyblom H, Bjornsson E, Simren M, Aldenborg F, Almer S, Olsson R. The AST/ALT ratio as an indicator of cirrhosis in patients with PBC. Liver Int. 2006;26(7):840-5. doi: 10.1111/j.1478-3231.2006.01304.x.

34. Abraham P, Rabi S. Nitrosative stress, protein tyrosine nitration, PARP activation and NAD depletion in the kidneys of rats after single dose of cyclophosphamide. Clin Exp Nephrol. 2009;13(4):281-7. doi: 10.1007/s10157-0090160-z.

35. Abraham $\mathrm{P}$, Indirani K, Sugumar E. Effect of cyclophosphamide treatment on selected lysosomal enzymes in the kidney of rats. Exp Toxicol Pathol. 2007;59(2):143-9. doi: 10.1016/j.etp.2007.05.003.

36. Humphreys BD. Kidney injury, stem cells and regeneration. Curr Opin Nephrol Hypertens. 2014;23(1):25-31. doi: 10.1097/01.mnh.0000437332.31418.e0.

37. Perazella MA. Onco-nephrology: renal toxicities of chemotherapeutic agents. Clin J Am Soc Nephrol. 2012;7(10):1713-21. doi: 10.2215/cjn.02780312. 